\title{
Foliar application of microbial-enriched compost tea enhances growth, yield and quality of muskmelon (Cucumis melo L.) cultivated under fertigation system
}

\begin{abstract}
Microbial-enriched compost tea (CT) is a water extract of compost that is amended with nutrient supplements during brewing to enhance their microbial diversity. The potential use of fertigation nutrients via drip irrigation system followed by weekly foliar application of microbial-enriched CT on growth of muskmelon (Cucumis melo L.) and suppression of powdery mildew caused by Golovinomyces cichoracearum DC. was studied under rain shelter conditions. Full and half strength fertigation nutrients in combination with weekly foliar application of microbial-enriched CT, fungicide (Daconil@@ @2 g L-1) or water as a control were utilised in this study. The study showed that there was no added advantage in using full strength fertigation nutrients in terms of chlorophyll content, mean flower formation, mean fruit set, disease severity, and disease progress (AUDPC) or epidemic rate. A repeat trial was also conducted using half strength fertigation nutrients (twice a day) in combination with weekly foliar application of microbial-enriched CT or Daconil®, as a result there was reductions in the disease severity by 38 and $21 \%$, respectively. In addition, a delay in disease onset for two weeks was observed in the plants treated with either microbialenriched CT or Daconil ${ }^{\circledR}$. The experimental results revealed significant variations in the yield and fruit qualities amongst the treatments. There were 18.3, 16.21, 8.81, 7.11 and $7.50 \%$ increases in mean fruit fresh weight $(\mathrm{kg})$, total soluble solids concentration ( $\left.{ }^{\circ} \mathrm{Brix}\right)$, firmness $(\mathrm{N})$, linear increment in the diameter $(\mathrm{cm})$ and mesocarp size $(\mathrm{cm})$ of muskmelon fruits, respectively after the application of half strength fertigation nutrients in combination with the weekly foliar application of microbial-enriched CT as compared with the control. Thus, it is rational to conclude that a reduced strength of the nutrients in the fertigation systems in combination with weekly foliar application of microbial-enriched CT could be used successfully as a biofertiliser and a bioprotectant on muskmelon crop without compromising their fruit quality.
\end{abstract}

Keyword: Fertigation system; Fruit quality; Inorganic fertilisers; Foliar application of compost tea; Plant growth; Golovinomyces cichoracearum DC 